\title{
MicroRNA miR-320a and miR-140 inhibit mink enteritis virus infection by repression of its receptor, feline transferrin receptor
}

\author{
Jia-zeng Sun, Jigui Wang, Shuang Wang, Daoli Yuan, Zhili Li, Bao Yi, Qiang Hou, Yaping Mao and Weiquan Liu*
}

\begin{abstract}
Mink enteritis virus (MEV) is one of the most important pathogens in the mink industry. Recent studies have shed light into the role of microRNAs (miRNAs), small noncoding RNAs of length ranging from 18-23 nucleotides (nt), as critical modulators in the host-pathogen interaction networks. We previously showed that miRNA miR-181b can inhibit MEV replication by repression of viral non-structural protein 1 expression. Here, we report that two other miRNAs (miR-320a and miR-140) inhibit MEV entry into feline kidney (F81) cells by downregulating its receptor, transferrin receptor (TfR), by targeting the $3^{\prime}$ untranslated region (UTR) of TfR mRNA, while being themselves upregulated.
\end{abstract}

Keywords: Mink enteritis virus (MEV), miR-320a, miR-140, Transferrin receptor (TfR)

\section{Introduction}

Mink enteritis virus (MEV) is an autonomous parvovirus that causes important disease in mink, leading to huge economic losses worldwide. MEV is a single-stranded negative sense DNA virus belonging to the family Parvoviridae, with a genome of about $5 \mathrm{~kb}$ containing 2 main open reading frames (ORFs). MEV, a variant of feline panleukopenia virus (FPV) and highly homologous with canine parvovirus (CPV), causes a highly infectious acute disease of mink characterized by extensive virus replication in mesenteric lymph nodes and intestinal crypt epithelial cells, with an associated loss of intestinal mucosa, diarrhea, and a high rate of morbidity and mortality [1-5].

MicroRNAs (miRNAs) are endogenous and highly conserved small noncoding RNAs of length 18-23 nucleotides (nt), which have gained widespread attention as critical modulators in many biological processes including cell proliferation and differentiation, development and apoptosis. In animals, miRNAs are imprecisely complimentary to their mRNA targets and act by repression of target gene expression [6-9].

* Correspondence: weiquan8@cau.edu.cn

State Key Laboratory of Agrobiotechnology, Department of Biochemistry and Molecular Biology, College of Biological Sciences, China Agricultural

University, No. 2 Yuanmingyuan West Road, Haidian District, Beijing 100193, China

\section{Biomed Central}

(c) 2014 Sun et al.; licensee BioMed Central Ltd. This is an Open Access article distributed under the terms of the Creative Commons Attribution License (http://creativecommons.org/licenses/by/4.0), which permits unrestricted use, distribution, and reproduction in any medium, provided the original work is properly credited. The Creative Commons Public Domain Dedication waiver (http://creativecommons.org/publicdomain/zero/1.0/) applies to the data made available in this article, unless otherwise stated.
Attention has also been paid to the role of miRNAs as effectors in host-virus interaction networks [10,11], either by targeting cellular factors useful for virus replication $[12,13]$ or by directly targeting virus mRNAs [14-17]. We have recently reported that a cellular miRNA miR-181b inhibits MEV infection by repression of viral non-structural protein 1 expression [18], which indicates that cellular miRNAs may play a direct role on viral mRNAs themselves.

For many animal viruses, cell entry and infection are initiated by receptor-mediated endocytosis involving specific cellular surface components. Transferrin receptor (TfR), is required for the import of iron into the cell, and is regulated by intracellular iron concentration. It has also been reported to be a receptor for MEV, controlling the first step in the viral infection process. TfR can be considered a model for the endocytosis and recycling of receptor-ligand complexes: it is excluded from lipid raft domains in the plasma membrane and is taken up rapidly from the cell surface via clathrin-mediated endocytosis [1,19-24]. Since TfR plays an important role in MEV infection, we therefore investigated whether miRNAs participate in the hostvirus interaction by modulating its activity.

\section{Materials and methods}

\section{Cell culture and MEV infection}

Feline F81 cells, obtained from the American Type Culture Collection (ATCC), were cultured as monolayers 
in minimum essential medium (MEM) (Gibco, CA) containing 10\% FBS (Hyclone, Logan, UT), and 1\% penicillinstreptomycin (Gibco) at $37^{\circ} \mathrm{C}$ in a $5 \% \mathrm{CO}_{2}$ atmosphere. $\mathrm{MEV}$ strain $\mathrm{L}$ was originally isolated from an infected animal in a mink farm, Liaoning province, China. The whole viral genome has been sequenced in our laboratory and found to have high identity with MEV strain Abashiri (GenBank accession, D00765.1). For infection, F81 cell monolayers were first dispersed by $0.25 \%$ trypsin and virus was added to the suspension before incubation in the original plates.

\section{Deep sequencing of small RNAs and analysis of the sequencing data [25]}

F81 cells cultured in 6-well plates (Costar) were infected with MEV at an input multiplicity (MOI) of 1 pfu/cell. Uninfected cells were maintained as a control. Twenty-four $h$ later, the triplicate cultures were pooled, total RNA was extracted by Trizol reagent (Invitrogen) and small RNAs with length of 18-30 nt were separated by PAGE. Ten $\mu \mathrm{g}$ samples of the isolated RNAs were submitted to Solexa (Illumina) for sequencing as cDNA libraries. Duplicate sequences were eliminated from the initial data set. The resulting sets of unique reads were mapped onto the feline genome [26,27] using the program Short Oligonucleotide Analysis Package (SOAP) [28]. Perfectly matched reads were also mapped onto the miRNAs of six reference species (Homo sapiens, Canis familiaris, Mus musculus, Rattus norvegicus, Bos taurus and Sus scrofa) listed in the Sanger miRBase (Release 18) using the Patscan tool [29] to identify homologs of known miRNAs.

\section{Prediction of miRNA targets in feline TfR mRNA 3'UTR}

RNAhybrid tools (http://bibiserv.techfak.uni-bielefeld.de/ rnahybrid/submission.html/) [30] were used to predict miRNA targets in TfR mRNA 3'UTR following the rules of no mismatch and G/U complementarity in miRNA seed sequences. RegRNA tools (http://vita.mbc.nctu.edu.tw/) [31] were also used to predict regulatory RNA motifs in the TfR mRNA 3'UTR. TargetScan (http://www.targetscan. org/) tools were used to predict conservative miRNA targets in the TfR mRNA 3'UTRs of different species.

\section{Plasmid construction}

The luciferase expression vector pGL3-control (Promega) was used for construction of predicted miRNA candidate targets containing a luciferase reporter gene, with pRL-TK (Promega) as control. Sequences containing part of the TfR 3'UTR and candidate targets of miRNAs were amplified by RT-PCR and directionally inserted into the 3'UTR of the luciferase gene in the pGL3-control vector, generating pGL3-TfR 3'UTR. To facilitate cloning, the first PCR product amplified by the first pair of primers (5' -ATGTGGTACCTATACTTATATGAGAAC-3' and 5'-
TCCGTGTTCAAGCATTTTATTAAATC-3') was used as a template and an $\mathrm{Xba}$ I restriction site (italics) was added to the 5'- (5'-GCTCTAGAATGTGGTACCTAT ACTTATATGAGAACAGC-3') and 3' - (5'-GCTCTAGA TCCGTGTTCAAGCATTTTATTAAATCAG-3') secondary pair of primers. To further ascertain that the binding sites of the predicted miRNAs in TfR 3'UTR indeed existed, tetranucleotide mutations were generated in the two potential target sites of pGL3-TfR 3'UTR using PCR, resulting in mut320a-pGL3-TfR 3'UTR (5'-CACTAG ATTTCTTTAGGCAGCACGAATTAATACAGGGTAGG TAC-3' and 5'-GTACCTACCCTGTATTAATTCGTGC TGCCTAAAGAAATCTAGTG-3') and mut140-pGL3TfR 3'UTR (5'-CTTCAAGTTAAAGTGAATAAGGTGT TAAAAATGTTCATGATAGAATC-3' and 5'-GATTCT ATCATGAACATTTTTAACACCTTATTCACTTTAACT TGAAG-3'). Mutant plasmids were generated by PCR using PrimeSTAR MAX DNA Polymerase (TaKaRa), 50 ng of the parent vectors as templates and the complementary primers under the following conditions: $98^{\circ} \mathrm{C}$ for 3 min, followed by 30 cycles of $98^{\circ} \mathrm{C}$ for $10 \mathrm{~s}, 55^{\circ} \mathrm{C}$ for $15 \mathrm{~s}$ and $72^{\circ} \mathrm{C}$ for $90 \mathrm{~s}$, followed by $72^{\circ} \mathrm{C} 10 \mathrm{~min}$. The resulting products were digested with $1 \mu \mathrm{l} \mathrm{Dpn-1}$ for $1 \mathrm{~h}$ at $37^{\circ} \mathrm{C}$ to remove the parental DNA. The remaining DNA was used to transform competent DH5 $\alpha$ cells, and a number of colonies containing mutant plasmids were obtained and confirmed by sequencing (Shanghai Sangong Co.).

\section{miRNA mimics and inhibitors}

The miR-320a, miR-320b, miR-140, miR-145, miR-152, miR-182 and miR-194 mimics and inhibitors, mut miR320 mimics (in which the tetranucleotide mutation was complementary to mut320 pGL3-TfR 3'UTR) and mut miR-140 mimics (in which the tetranucleotide mutation was complementary to mut140 pGL3-TfR 3'UTR) were synthesized by GenePharma, Shanghai. All mimics were double-stranded RNA oligos, while inhibitors were singlestranded. Negative control mimics and inhibitors were also synthesized for control experiments. The inhibitors were modified by 2'-O-methylation. All sequences of mimics and inhibitors are listed below (italic letters are mutated bases):

miR-320a mimics: 5' ${ }^{\prime}$-AAAAGCUGGGUUGAGAGGG CGA-3'

miR-320a inhibitors: 5'-UCGCCCUCUCAACCCAGC UUUU-3'

miR-320b mimics: 5'-AAAAGCUGGGUUGAGAGGG CAA-3'

miR-320b inhibitors: 5'-UUGCCCUCUCAACCCAG CUUUU-3'

miR-140 mimics: 5 '-CAGUGGUUUUACCCUAUG GUAG-3'

miR-140 inhibitors: $5^{\prime}$-CUACCAUAGGGUAAAACCA CUG-3' 
miR-145 mimics: 5'-GUCCAGUUUUCCCAGGAAUC CCU-3'

miR-145 inhibitors: $5^{\prime}$-AGGGAUUCCUGGGAAAACU GGAC-3'

miR-152 mimics: 5' -UCAGUGCAUGACAGAACUUGG-3' miR-152 inhibitors: 5'-CCAAGUUCUGUCAUGCAC UGA-3'

miR-182 mimics: 5'-UUUGGCAAUGGUAGAACUCA CACU-3'

miR-182 inhibitors: 5'-AGUGUGAGUUCUACCAUUG

CCAAA-3'

miR-194 mimics: 5'-UGUAACAGCAACUCCAUGU GGA-3'

miR-194 inhibitors: 5' -UCCACAUGGAGUUGCUGUU ACA-3'

Mut miR-320a mimics: 5'-AAUUCGUGGGUUGAGA GGGCGA-3'

Mut miR-140 mimics: 5' -CACACCUUUUACCCUAU GGUAG-3'

Negative control (NC) mimics: 5'-UUCUCCGAACGU GUCACGUTT-3'

Negative control (NC) inhibitors: 5'-CAGUACUUUU GUGUAGUACAA-3'

\section{Transfection}

To screen for selected miRNAs to downregulate the expression of TfR, F81 cells, at a confluence of $60-70 \%$ in 24-well plates (Costar), were transfected with mimics or inhibitors $(10 \mathrm{nM})$ using Lipofectamine 2000 transfection reagent (Invitrogen). NC mimics and inhibitors were used as controls. To further determine whether the screened miRNAs could modulate the expression of TfR, F81 cells were transfected with the mimics in a dosedependent manner. The cells were collected for TfR mRNA qPCR assay at $36 \mathrm{~h}$ post-transfection and western blot analysis and flow cytometry assay at $48 \mathrm{~h}$.

To determine whether the selected miRNAs play a direct role in repression of luciferase expression from pGL3-TfR 3'UTR, 24-well plates seeded with F81 cells at $60-70 \%$ confluence were co-transfected with a mixture of pGL3-TfR 3'UTR $(4 \mu \mathrm{g} / \mathrm{ml})$ and pRL-TK vector $(4 \mu \mathrm{g} / \mathrm{ml})$ together with mimics $(10 \mathrm{nM})$. The mut320a or mut140 pGL3-TfR 3'UTR and pRL-TK together with mimics $(10 \mathrm{nM})$ were co-transfected to verify accuracy of the seed sequence. NC mimics were used as negative controls. After $36 \mathrm{~h}$, the cells were harvested for relative luciferase activity assay.

To determine the effects of the selected miRNAs on MEV infection, F81 cells, at a confluence of $60-70 \%$ in 24-well plates, were transfected with mimics $(10 \mathrm{nM})$. After $48 \mathrm{~h}$, the cells were dispersed with $0.25 \%$ trypsin and infected with MEV (MOI =0.1). Virus infection was measured by qPCR and flow cytometric analysis at the indicated times.

\section{Luciferase assays}

To quantify the relative luciferase activity, a dual-luciferase reporter assay system kit (Promega) was used according to the manufacturer's protocol. Co-transfected cells with a mixture of luciferase reporter plasmids were washed with cold phosphate-buffered saline (PBS). Passive lysis buffer (Promega: $100 \mu \mathrm{l}$ ) was then added to the cells in each well. After $10 \mathrm{~min}$, the supernatants were clarified by centrifugation at 12,000 g for $30 \mathrm{~s}$, and the luciferase activity was measured using a Modulus single-tube multimode reader (Promega). Relative luciferase expression was calculated as the expression of firefly luciferase (pGL3-control vector) divided by that of Renilla luciferase (pRL-TK).

\section{Real-time quantitative PCR (qPCR) analysis}

To detect whether selected miRNAs can downregulate the expression of TfR, qPCR analysis was performed. After transfection of F81 cells with miRNA mimics or inhibitors, NC mimics or inhibitors as controls, total RNA was extracted and digested with DNase I (Takara). Two $\mu$ g total RNA of each sample was reverse transcribed using MMLV reverse transcriptase (Promega) according to the manufacturer's protocol. The $\beta$-actin mRNA level was measured as a control. Primers used for amplification were: $\beta$-actin, 5 '-CGGGACCTGACGGACTACCT-3' and $5^{\prime}$-GGCCATCTCCTGCTCAAAAT-3' and TfR, $5^{\prime}$-ATG ATTGGCTACTTGGGCTATTG- 3 ' and $5^{\prime}$-CCTGATGG TGCTGGTGAACTC-3'.

To detect the viral genomic DNA quantitative level in F81 cells, total DNA was extracted and the concentration was measured. PCR amplication of a fragment of viral genomic DNA (5'-GCTTACGCTGCTTATCTTCGC-3', 5'-TAATGTCCTATTTTCCCCCCC-3') was performed.

To determine the expression level of miRNAs in F81 cells, total RNA was extracted, and $2 \mu \mathrm{g}$ was polyadenylated using $E$. coli poly (A) polymerase according to the manufacturer's protocol (Promega). The poly (A) reaction product was then reverse transcribed using M-MLV reverse transcriptase (Promega) and an adaptor primer [32] (5'-GCGAGCACAGAATTAATACGACTCACTAT AGGTTTTTTTTTTTTVN-3') according to the manufacturer's protocol. PCR amplication was carried out using the specific miRNAs primers (miR-320a, 5'-AAAAGCG GGGAGAGGGCG-3' and $5^{\prime}$-GCGAGCACAGAATTAAT ACGACTCAC-3' and miR-140, 5'-CAGTGGTTTTACC CTATGGTAGAAA-3' and 5'-GCGAGCACAGAATTAA TACGACTCAC-3'). U6 small RNA expression level was measured as a control using primers $5^{\prime}$-CTCGCTT CGGCAGCACA-3' and 5'-AACGCTTCACGAATTTG CGT-3'. Cycling conditions for qPCR using FastSYBR Mixture (CWBIO) and the ViiA ${ }^{\mathrm{m}} 7$ real-time PCR System (Applied Biosystems) were $95^{\circ} \mathrm{C}$ for $20 \mathrm{~s}$, followed by 35 cycles of $95^{\circ} \mathrm{C}$ for $3 \mathrm{~s}$ and $60^{\circ} \mathrm{C}$ for $30 \mathrm{~s}$. The data were analyzed by the $\Delta \Delta \mathrm{Ct}$ method [33]. 


\section{Western blot assay}

F81 cells transfected with mimics in a 24-well plate were washed 3 times with cold PBS, a mixture of $100 \mu$ RIPA lysis buffer (HX-BIO) and 0.5 mM PSMF was added and the cells were harvested into Eppendorf tubes. After $30 \mathrm{~min}$ on ice and centrifugation at $12,000 \mathrm{~g}$ for $30 \mathrm{~min}$, $25 \mu \mathrm{l}$ supernatant was mixed with $25 \mu \mathrm{l}$ each $2 \times$ SDS sample buffer and boiled for $5 \mathrm{~min}$. Samples were subjected to $10 \%$ SDS-PAGE gel and transferred to a nitrocellulose membrane (PALL Life Science). The membranes were blocked with $5 \%$ nonfat dry milk for $1 \mathrm{~h}$, then incubated for $1 \mathrm{~h}$ at room temperature with purified primary mouse antibody CD71 (H68.4) (Santa Cruz: 1:500 dilution) or anti- $\beta$-actin antibody (MBL: 1:1,000 dilution) in nonfat milk. After 3 washes with Tris-buffered saline containing 0.05\% Tween-20 (TBST), the membranes were incubated for $1 \mathrm{~h}$ at ambient temperature with the appropriate horseradish peroxidase-conjugated secondary antibody (MBL: 1:5,000 dilution) in TBST. Protein bands were visualized using ECL western blot substrate (Thermo), with $\beta$ actin as a control.

\section{Flow cytometry}

Treated F81 cell monolayers were dispersed with $0.25 \%$ trypsin, harvested and fixed in 4\% paraformaldehyde. After 3 washes with $\mathrm{PBS}$ and incubation for $1 \mathrm{~h}$ at $37^{\circ} \mathrm{C}$ with anti-CD71 mouse antibody (1:2500) or anti-MEV rabbit polyclonal antibody (prepared in this laboratory) at 1:100, the cells were washed 3 times with PBS, incubated with fluorescein isothiocyanate (FITC)-conjugated goat antimouse or anti-rabbit IgG antibody (MBL: 1:100 dilution) for $1 \mathrm{~h}$ at $37^{\circ} \mathrm{C}$, washed another 3 times with PBS and analysed by BD FACSCalibur flow cytometry. Nonspecific rabbit polyclonal antibody (iso) (prepared in this laboratory) was used as an isotype control. The data were analyzed using BD CellQuest software.

\section{Argonaute 2 (Ago2) co-immunoprecipitation}

Human anti-Ago2 antibody (Abnova) was first bound to protein A/G-Agarose (Abmart) in PBS for $30 \mathrm{~min}$ at $4^{\circ} \mathrm{C}$. Treated F81 cells were harvested, washed and solubilized in RIPA lysis buffer (HX-BIO) and PSMF for $30 \mathrm{~min}$ on ice, then centrifuged at 12,000 g for 30 min to clarify the supernatant. The latter was then added to the Ago2/Agarose conjugate and incubated for $4 \mathrm{~h}$ at $4^{\circ} \mathrm{C}$. Incubation of the supernatant with normal mouse IgG (MBL) was used as a negative control. RNA bound to the Ago 2 protein was dissociated with Trizol reagent and reverse transcribed. TfR, miR-320a and miR-140 were quantified by qPCR analysis, with $\beta$-actin and U6 small RNA as internal controls.

\section{Statistical analysis}

Data were analysed statistically using GraphPad software, as described in the figure legends.

\section{Results}

Screening of miRNAs targeting TfR mRNA 3'UTR

As described in Materials and Methods, small RNA ultrahigh throughput sequencing was performed (Solexa) on uninfected F81 cells and following MEV infection $(\mathrm{MOI}=1)$ to detect miRNAs targeting TfR 3'UTR. Two miRNA libraries were also constructed [34]. Screening for miRNAs with RNAhybrid [30], RegRNA [31] and TargetScan tools identified 6 miRNA candidates (Figure 1). To test these miRNAs, F81 cells were transfected with the miRNA mimics and inhibitors, negative control (NC) mimics and inhibitors as controls. After 36 h, TfR mRNAs were quantified by qPCR. Results showed that miR-320a and miR140 mimics decreased TfR mRNA levels by almost 30\% compared to NC mimics, and miR-320a inhibitors increased them approximately 25\% (Figure 2A). After $48 \mathrm{~h}$ transfection as above, the quantity of TfR proteins were also examined by western blot and flow cytometry. Results showed that miR-320a and miR-140 downregulated the protein level (Figure 2B) and the percentage of TfR-positive cells by almost $20 \%$ and $30 \%$ respectively (Figure 2C). To further confirm the activity of the mimics, qPCR and western blot assay were used to show that the expression levels of TfR were reduced in a dose-dependent manner (Figure 1D,E). Altogether, these results clearly show that cellular miR-320a and miR-140 have negative effects on TfR expression.

\section{MEV infection leads to cellular miR-320a and miR-140 upregulation and TfR downregulation}

The expression levels of predicted miRNAs are shown in Table 1. Following MEV infection both miR-320a and miR-140 showed relatively higher level expression and greater upregulation than found in uninfected cells. This was confirmed by qPCR which showed that both miRNAs gradually increased following MEV infection (Figure 3). To investigate whether upregulation of the two miRNAs following MEV infection could affect TfR expression, qPCR (Figure 3A,B) and western blot (Figure 3C) were performed simultaneously. As expected, TfR was gradually downregulated following MEV infection. To further ascertain that TfR downregulation is the result of miRNAs upregulation, F81 cells were transfected with miRNA inhibitors $12 \mathrm{~h}$ post MEV infection. Results showed that compared with transfection with NC inhibitors, both miR320a and miR-140 inhibitors attenuated the inhibitory effect on TfR expression levels (Figure 3D). It appears, therefore, that upregulation of miR-320a and miR-140 directly results in TfR downregulation.

\section{MiR-320a and miR-140 target the 3'UTR of TfR and physically bind to TfR mRNA in the RISC}

To confirm that miR-320a and miR-140 directly target TfR 3'UTR and show inhibitory activity, a reporter vector pGL3-TfR 3'UTR containing the potential target 


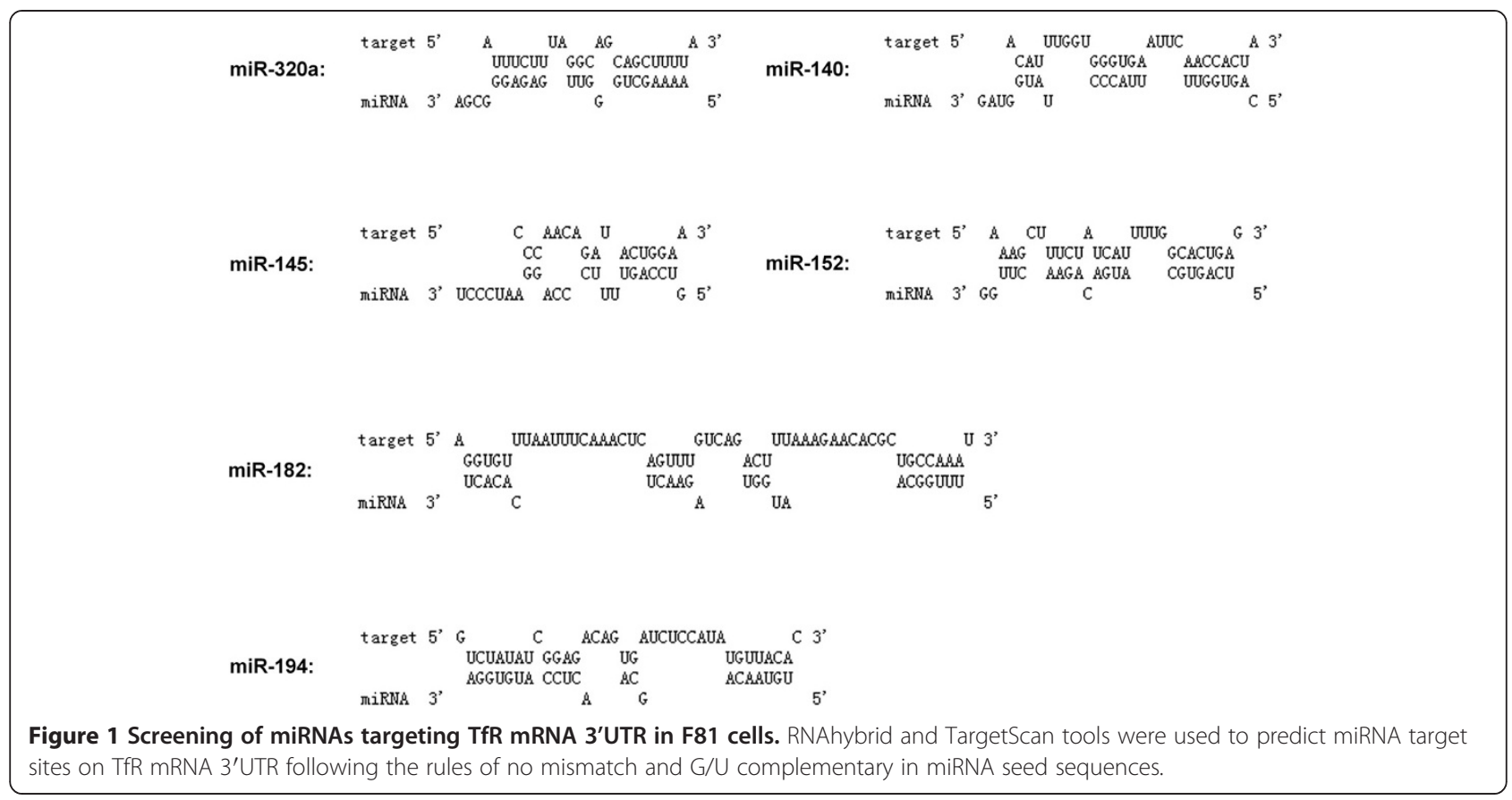

A

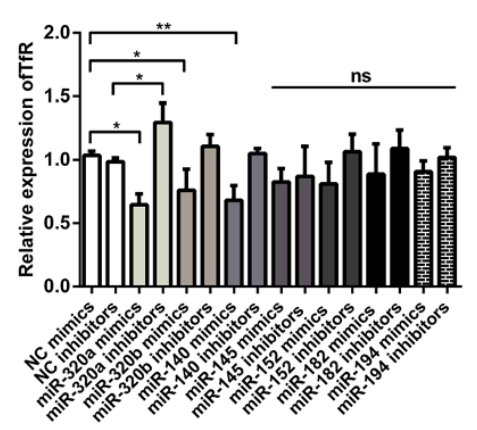

C

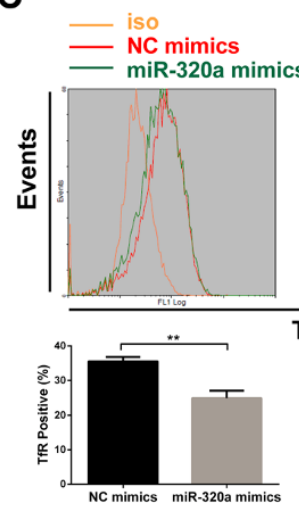

- iso - NC mimics —_ miR-140 mimics
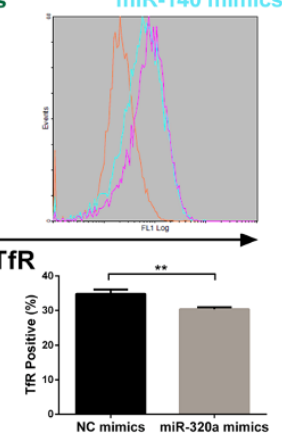

B $\begin{array}{llllllllll}1 & 2 & 3 & 4 & 5 & 6 & 7 & 8 & 9 & 10\end{array}$ TfR

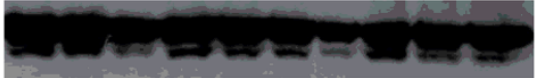

$\beta$-actin


Figure 2 MiR-320a and miR-140 inhibits TfR expression in F81 cells. (A) qPCR was used to assess effects of predicted miRNA mimics and inhibitors on the relative expression of TfR after $36 \mathrm{~h}$ transfection with either mimics or inhibitors, with $\beta$-actin as an internal control. (B) Western blot assay was used to assess the TfR protein levels of lysates of F81 cells after $48 \mathrm{~h}$ transfection with either mimics or inhibitors. (C) Flow cytometric analysis was used to assess the percentage of TfR-positive F81 cells after $48 \mathrm{~h}$ transfection with miR-320a and miR-140 mimics. (D) qPCR was used to assess the TfR mRNA levels after $36 \mathrm{~h}$ transfection with miR-320a and miR-140 mimics in a dose-dependent manner (E) Western blot assay was used to assess the TfR protein levels after $48 \mathrm{~h}$ transfection with miR-320 and miR-140 mimics in a dose-dependent manner. Data are from 3 independent experiments (mean \pm SD). Statistical significance was analyzed by Student's $t$ test; ${ }^{*} P<0.05 ;{ }^{* *} P<0.01$; ns, not significant. 
Table 1 Expression level of the predicted miRNAs of the two libraries

\begin{tabular}{lcccc}
\hline miRNAs & Rds num $^{\mathbf{a}}$ in mock infected cells & Rds num in $\mathbf{M E V}$ infected cells & TPM $^{\mathbf{b}}$ in mock infected cells & TPM in MEV infected cells \\
\hline miR-320a & 2432 & 64835 & 427.85 & 11566.02 \\
miR-140 & 3005 & 8894 & 528.66 & 1586.61 \\
miR-145 & 1181 & 668 & 207.77 & 119.17 \\
miR-152 & 1208 & 561 & 212.52 & 100.08 \\
miR-182 & 3094 & 5846 & 544.3 & 1042.88 \\
miR-194 & 388 & 1 & 68.26 & 0.18 \\
\hline
\end{tabular}

${ }^{\mathrm{a}} \mathrm{Rds}$ mum: Reads number.

${ }^{\mathrm{b}}$ TPM: Tags per million.

segment in the 3'UTR of the luciferase gene was constructed (Figure 4A). After co-transfection of F81 cells with pGL3-TfR 3'UTR and miR-320a or miR-140 mimics, the relative luciferase activity was measured. As predicted, both miR-320a and miR-140 significantly inhibited the relative luciferase activity (by more than half) in comparison with NC mimics (Figure 4B). To further ascertain the necessary function of complementary seed sequence, mut320a-pGL3-TfR 3'UTR and mut140-pGL3-TfR 3'UTR, with mutated tetranucleotides were constructed and the corresponding mut miR-320a and mut miR-140 mimics were synthesized (Figure 4A). As expected, after co-transfection of F81 cells, miR-320a and miR-140 mimics had no effect on the relative expression activity of the mutant reporter vector, but mut
miR-320a and mut miR-140 mimics downregulated them by more than 2 -fold (Figure 4C,D). To provide evidence for the physical interaction of the two miRNAs with TfR mRNA, immunoprecipitation with Argonaute 2 (Ago2) was performed. As previously described [35], both mRNA degradation and translation repression is dependent on RISC, in which the most important factor is Ago2 protein. Therefore, anti-Ago2 antibody was used to test if the two miRNAs and TfR mRNA were associated with Ago2. As expected, when Ago2 protein was specifically precipitated by anti-Ago 2 antibody, as compared with normal IgG, TfR was enriched more than 3-fold by miR-320a and more than 2-fold by miR-140 after transfection with miR-320a or miR-140 mimics respectively, whereas following transfection with mut miR-320a or mut miR-140, TfR was not

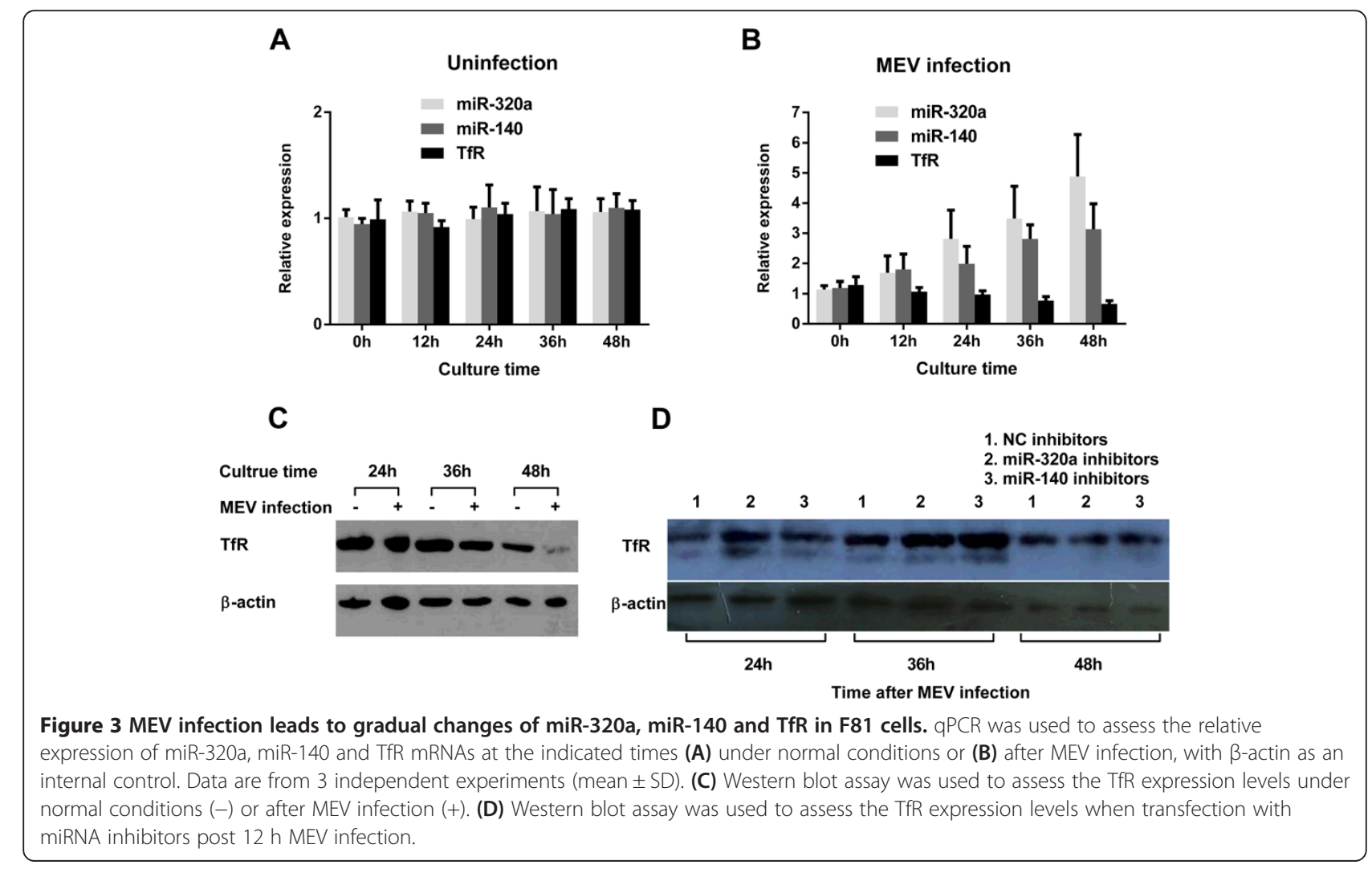




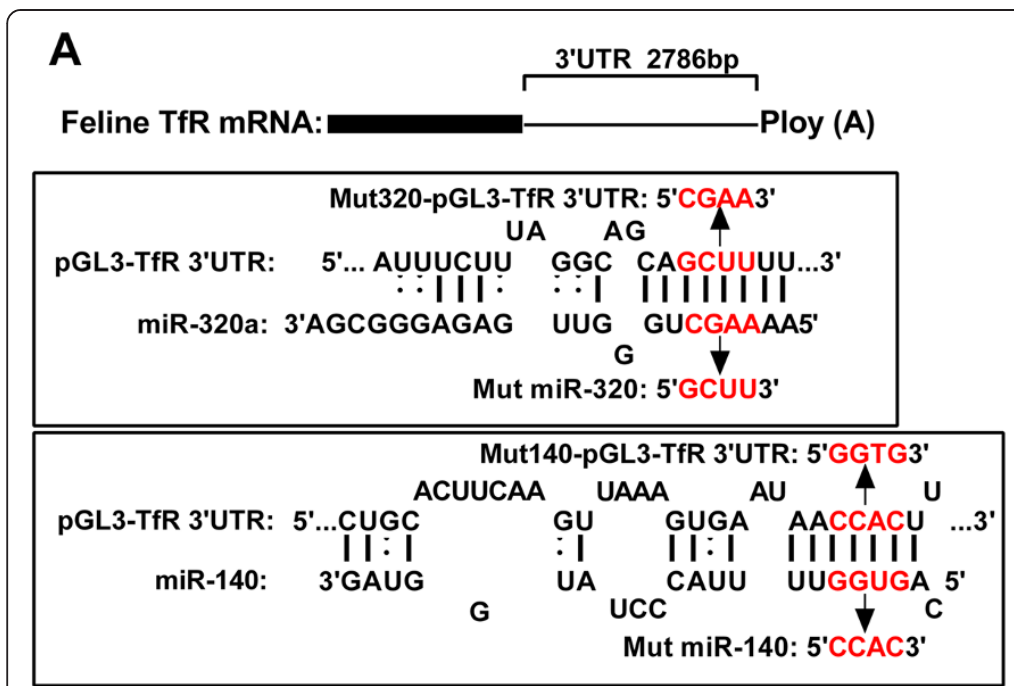

B

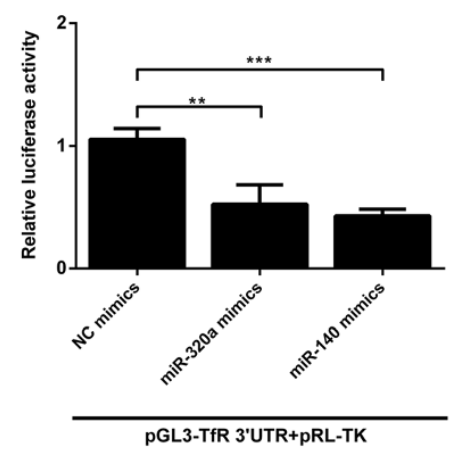

E

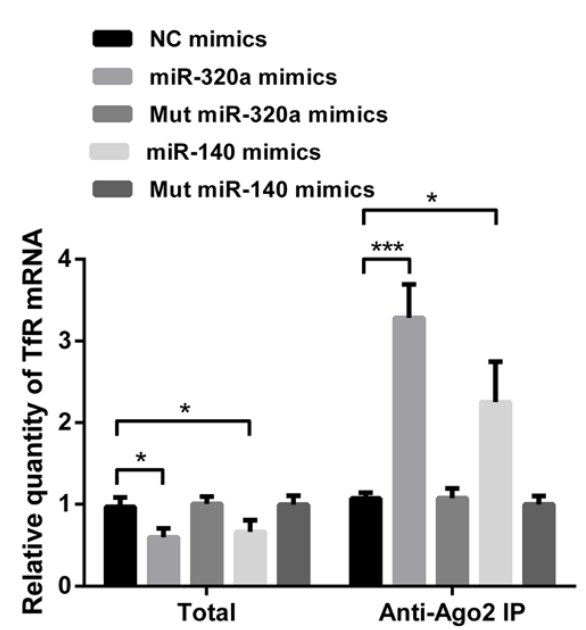

D

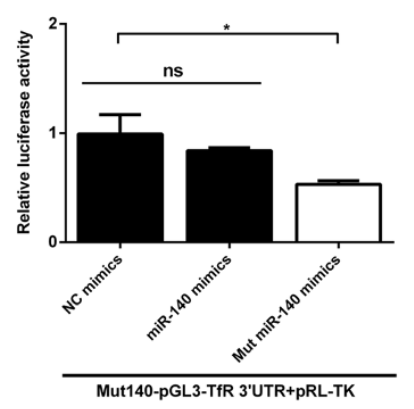

Figure 4 MiR-320a and miR-140 target the 3'UTR of TfR and physically bind to TfR mRNA in the RISC. (A) Schematic layout of TfR mRNA and presumptive targets of miR-320a and miR-140 via the sequential complementary nucleotides as indicated. The targets and tetranucleotide mutant targets segments were cloned into a pGL3-control reporter vector. The corresponding mut miR-320 and mut miR-140 were synthesized. (B) Luciferase activity of lysates of F81 cells after $36 \mathrm{~h}$ co-transfection with pGL3-TfR 3'UTR, pRL-TK and miR-320 or miR-140 mimics. NC mimics were used as controls. (C) Luciferase activity of lysates of F81 cells after 36 h co-transfection with mut320-pGL3-TfR 3'UTR, pRL-TK and miR-320a or mut miR-320a mimics. NC mimics were used as controls. (D) Luciferase activity of lysates of F81 cells after $36 \mathrm{~h}$ co-transfection with mut140-pGL3TfR 3'UTR, pRL-TK and miR-140 or mut miR-140 mimics. NC mimics were used as controls. (E) qPCR analysis of TfR mRNA among RNAs extracted from Ago2 immunoprecipitates or total samples of F81 cells, normalized to $\beta$-actin. Data are from 3 independent experiments (mean \pm SD). Statistical significance was analyzed by Student's $t$ test; ${ }^{*} P<0.05$; ${ }^{*} P<0.01$; ${ }^{* *} P<0.001$; ns, not significant.

enriched (Figure 4E). Altogether, these results indicate that miR-320a and miR-140 target the 3'UTR of TfR and physically bind to TfR mRNA in the RISC.

MiR-320a and miR-140 inhibit MEV infection by preventing the virus from entering cells

Since miR-320a and miR-140 downregulated TfR expression, we speculated that the two miRNAs could control MEV infection by preventing the virus from entering cells. To investigate this, F81 cells were transfected with either miR-320a and miR-140 mimics, with $\mathrm{NC}$ mimics as controls. After $48 \mathrm{~h}$ transfection, the cells were infected with $\mathrm{MEV}(\mathrm{MOI}=0.1)$. At the indicated times, the quantity of viral genomic DNA was measured. As predicted, results showed that miR-320a and miR-140 downregulated the quantity of viral genomic DNA in F81 cells, even during the early stage of virus infection (Figure 5A). To further validate the results above, flow cytometry was used to determine the proportion of MEV-infected cells. Results showed that compared with transfection with NC mimics, both miRNAs mimics had a negative effect on MEV-infected cell numbers from quite early on (Figure 5B,C,D,E). These results clearly demonstrated that miR-320a and miR-140 inhibit MEV infection by preventing virus entry into the cells. 

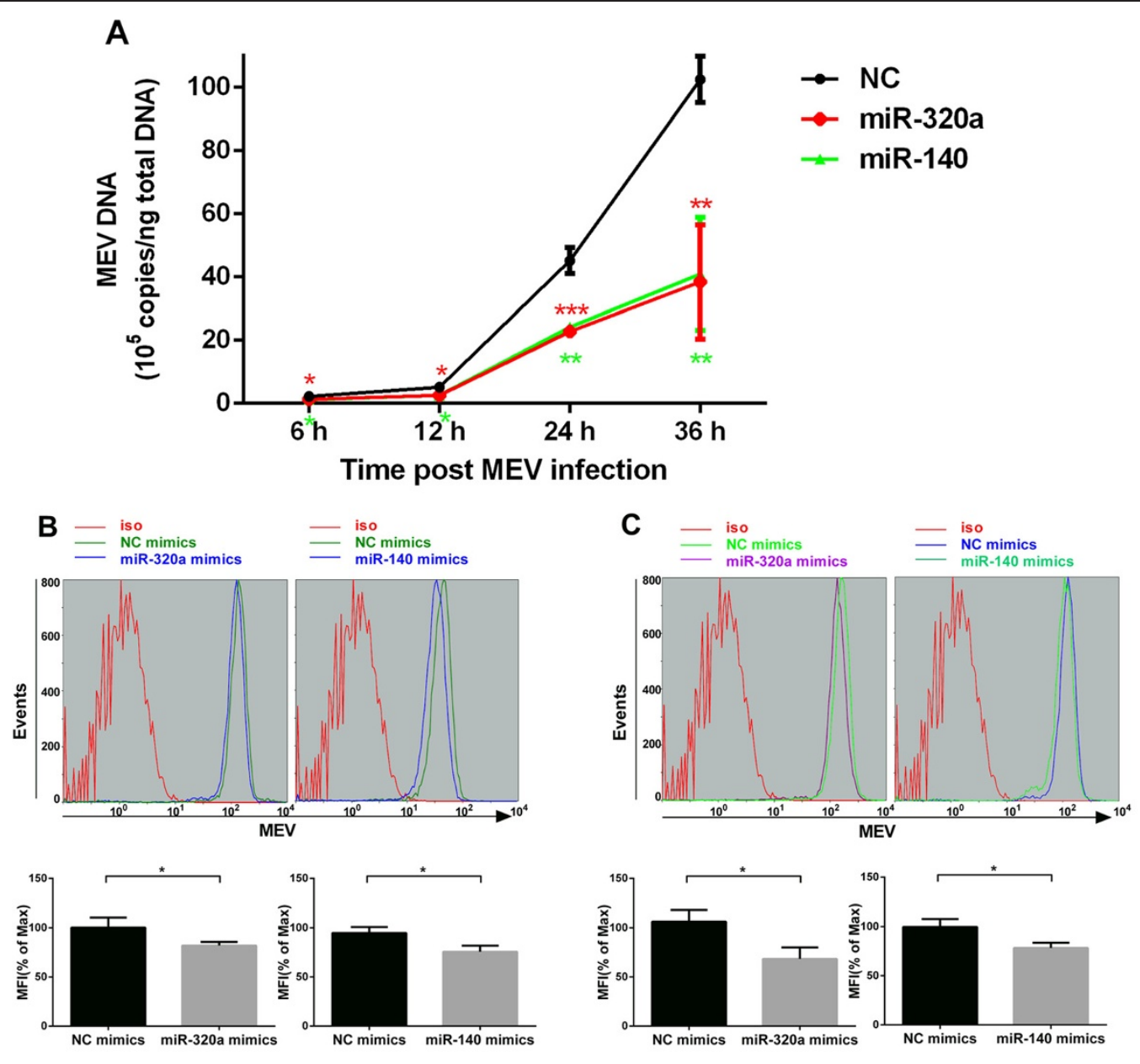

$6 \mathrm{~h}$ post MEV infection

12h post MEV infection
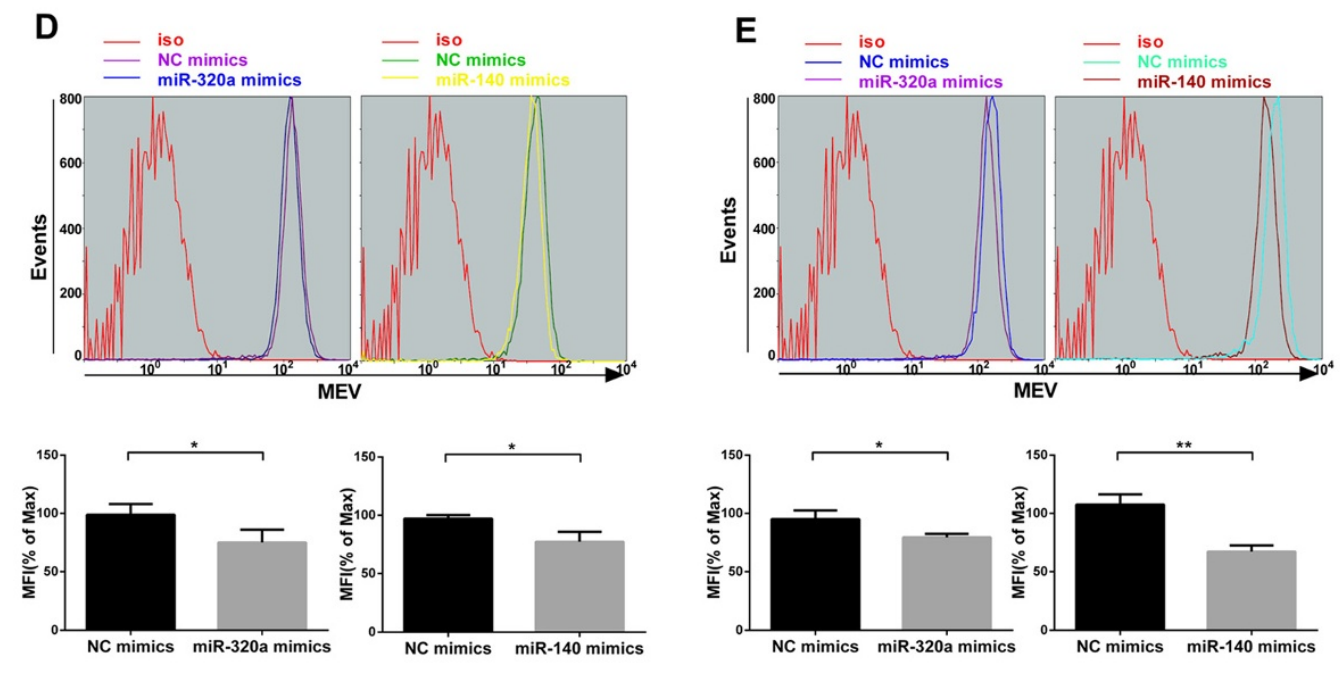

24h post MEV infection

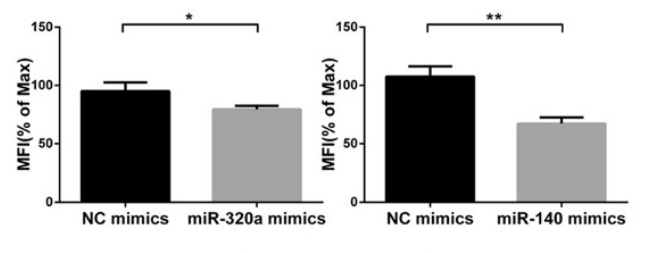

36h post MEV infection

Figure 5 (See legend on next page.) 
(See figure on previous page.)

Figure 5 MiR-320a and miR-140 inhibit MEV infection by preventing the virus to entry into F81 cells. (A) qPCR was used to assess the effects of miR-320a and miR-140 mimics of MEV genomic DNA at the indicated times after $48 \mathrm{~h}$ transfection with the mimics. Data are from 3 independent experiments (mean $\pm \mathrm{SD}$ ). Statistical significance was analyzed by two-way ANOVA test; ${ }^{*} P<0.05 ;{ }^{* *} P<0.01$; ${ }^{* * *} P<0.001$. (B,C,D,E) Flow cytometric analysis was used to assess the effects of miR-320a and miR-140 mimics on MEV-infected F81 cells at the indicated times after $48 \mathrm{~h}$ transfection with the mimics. The mean fluorescence intensities (MFI) of MEV-infected F81 cells at the indicated times are shown. Data are from 3 independent experiments (mean \pm SD). Statistical significance was analyzed by Student's $t$ test; ${ }^{*} P<0.05 ;{ }^{* *} P<0.01 ;{ }^{* * *} P<0.001$.

\section{MiR-320a and miR-140 play roles on TfR and MEV in a synergistic manner}

As described above, both miR-320a and miR-140 inhibit MEV infection by downregulating TfR expression. Since the targets in TfR 3'UTR of the two miRNAs are different, we speculated that the two miRNAs could show function together. To investigate this, F81 cells were transfected with miR-320a and miR-140 mimics individually or together, with NC mimics as controls. After $36 \mathrm{~h}$ transfection, TfR mRNAs were assayed by qPCR. Results showed that miR-320a and miR140 mimics together decreased TfR mRNA levels by almost 30\% compared to miR-320a or miR-140 mimics (Figure 6A). At $48 \mathrm{~h}$, western blot assay also showed that the decrease in TfR protein level was enhanced by the two miRNAs together (Figure 6B). To confirm that the two miRNAs also showed greater negative function on MEV infection, F81 cells were transfected with miR-320a and miR-140 mimics individually or together, with NC mimics as controls. After $48 \mathrm{~h}$ transfection, the cells were infected with $\mathrm{MEV}(\mathrm{MOI}=0.1)$ and
A



C

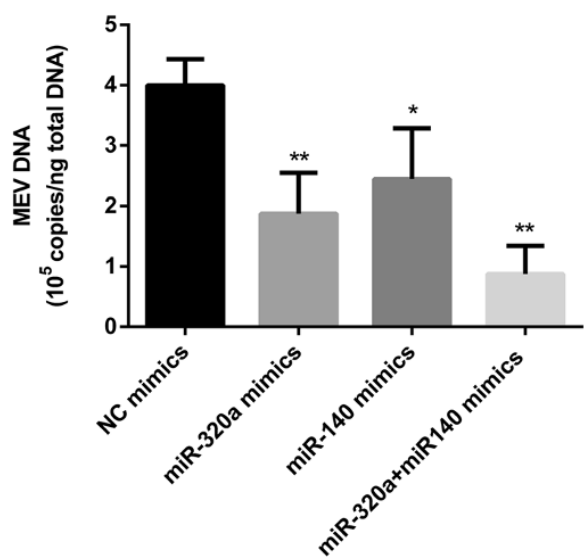

B

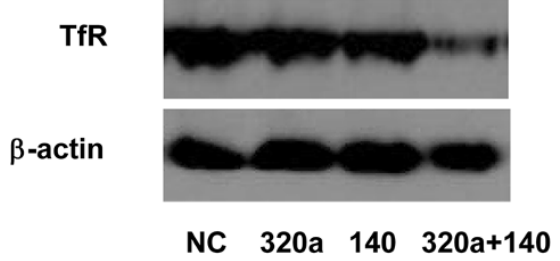

Figure 6 MiR-320a and miR-140 play roles on TfR and MEV in a synergistic manner. (A) qPCR was used to assess effects of the miRNAs on the relative expression of TfR after $36 \mathrm{~h}$ transfection with the mimics, with $\beta$-actin as an internal control. (B) Western blot assay was used to assess the TfR protein levels of lysates of F81 cells after $48 \mathrm{~h}$ transfection with the miRNAs mimics, with $\beta$-actin as an internal control. (C) qPCR was used to assess the effects of the miRNAs on MEV genomic DNA at $12 \mathrm{~h}$ post-MEV infection, after $48 \mathrm{~h}$ transfection with the mimics. Data are from 3 independent experiments (mean \pm SD). Statistical significance was analyzed by Student's $t$ test; ${ }^{*} P<0.05$; ${ }^{* *} P<0.01$. 
the viral genomic DNA measured $12 \mathrm{~h}$ later. As predicted, results showed that the two miRNAs together produced a greater reduction in viral genomic DNA than individually.

\section{Discussion}

Host cellular miRNAs have frequently been reported to interact with viruses during infection [10,15,35-40]. We recently showed that miR-181b inhibited MEV replication by repression of its non-structural protein 1 expression [18]. Here, we report that other miRNAs, miR-320a and miR-140, inhibit MEV entry into F81 cells by downregulating its receptor, TfR, through targeting the 3 'UTR of TfR mRNA.

A number of reports have shown that TfR, as a cell surface receptor, is required for iron delivery to cells. Indeed, TfR has been established as a gatekeeper for regulating iron uptake by most cells, and the transferring-to-cell endocytic pathway has been characterized in detail [41]. TfR is central to the uptake of iron-loaded transferrin [42] which is post-transcriptionally regulated via iron-responsive elements present in its 3'UTR [43]. In addition to its role in erythropoiesis, TfR is also overexpressed in the majority of malignancies [44] and is directly linked to cell proliferation [45-47]. Studies have demonstrated that parvovirus replication is dependent on host cellular division and proliferation ([48]; Tattersa [49]) and vigorous proliferative activity of host cells promotes parvoviral replication. Reduction in cellular metabolic activity, therefore, may explain why downregulation of TfR inhibits MEV replication. There may, however, be another mechanism. TfR is necessary for MEV uptake by host cells: downregulation may therefore render infected cells less susceptible to superinfection with additional MEV particles. While it may take only one virion to establish a primary infection, a multiply-infected cell may produce more infectious progeny. Downregulation of TfR on the cell surface, therefore, may result in diminished production of virus.

As summarized in Figure 7, MEV infection leads to increase in two host cell miRNAs (miR-320a and miR-140) which downregulate TfR expression, resulting in a decrease in viral replication. Since TfR is a specific receptor of MEV, however, reduction in it may prevent cellular entry of further virus following the primary infection, resulting in protection of host cells from immediate death as a result of continuing virus infection. Although two host cell miRNAs were found to be upregulated by MEV infection, the mechanism remains unclear. We have identified one mechanism of interaction between MEV and its host F81 cells, however, that might explain why a cell can be infected with just one virus.

Since miR-320a and miR-140 have been shown to inhibit MEV entry into host cells and might also affect virus replication, it may find application as an antiviral therapeutic for MEV-induced mink enteritis. As several reports have shown [50-54], siRNAs can be used to control virus diseases in vivo; however, little attention has so far been paid to the possibility of using endogenous miRNAs as an antivirus tool. Compared with siRNAs, endogenous miRNAs may be safer and induce fewer side-effects. More extensive studies are merited to determine if the two miRNAs described here can be used as antiviral tools.

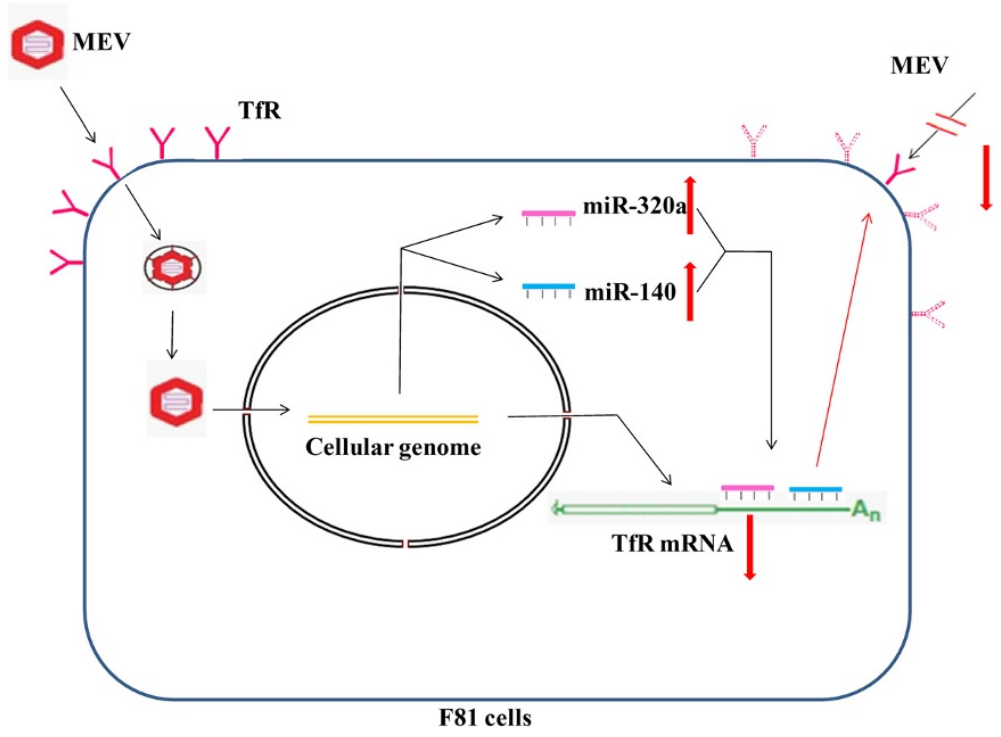

Figure 7 Schematic layout of the mechanism of interaction between MEV and its host F81 cells involving two miRNAs and TfR. (Up arrows: upregulation; down arrows: downregulation). 


\section{Conclusions}

In conclusion, our work has shown that two miRNAs (miR-320a and miR-140) inhibit MEV entry into the F81 cells by downregulating its specific receptor TfR through targeting the 3'UTR of TfR mRNA in a synergistic manner, while the two miRNAs were upregulated through MEV infection. As summarized in Figure 7, a simple pathway of host-virus interaction network involving TfR and miRNAs has been deduced. These results provide further understanding of the mechanisms in MEV infection and may be helpful for development of endogenous miRNA antiviral therapy strategies.

\section{Competing interests}

The authors declare that they have no competing interests.

\section{Authors' contributions}

JS and WL conceived and designed the experiments. JS performed the experiments. JS analyzed the data. JS, JW, SW, DY, ZL, BY, QH and YM contributed reagents/materials/analysis tools. JS and WL wrote the paper. All authors read and approved the final manuscript.

\section{Acknowledgements}

This work was supported by 863 Project (2011AA10A213) and National Key Scientific Foundation (2009ZX08006-010B).

\section{Received: 15 September 2014 Accepted: 19 November 2014}

\section{1.}

\section{References}

1. Park GS, Best SM, Bloom ME: Two mink parvoviruses use different cellular receptors for entry into CRFK cells. Virology 2005, 340:1-9.

2. Rivera E, Karlsson KA, Bergman R: The propagation of feline panleukopenia virus in microcarrier cell-culture and use of the inactivated virus in the protection of mink against viral-enteritis. Vet Microbiol 1987, 13:371-381.

3. Schofield FW: Virus enteritis in mink. North Amer Vet 1949, 30:651-654.

4. Zhang DL: Studies on isolation, serum-free cultivation and manufacture of mink enteritis virus optimized for vaccine preparation. Biologicals 1997, 25:103-111.

5. Zuo J, Rao J, Xu H, Ma L, Li B, Wang Y, Cai X, Han W, Lei L, Liu B: Analysis of the $v p 2$ gene sequence of a new mutated mink enteritis parvovirus strain in PR China. Virol J 2010, 7:124-129.

6. Ambros V: The functions of animal microRNAs. Nature 2004, 431:350-355

7. Bartel DP: MicroRNAs: Genomics, biogenesis, mechanism, and function. Cell 2004, 116:281-297.

8. Bartel DP: MicroRNAs: Genomics, biogenesis, mechanism, and function (Reprinted from Cell 116, 281-297, 2004). Cell 2007, 131:11-29.

9. Krol J, Loedige I, Filipowicz W: The widespread regulation of microRNA biogenesis, function and decay. Nat Rev Genet 2010, 11:597-610.

10. Cameron JE, Yin Q, Fewell C, Lacey M, McBride J, Wang X, Lin Z, Schaefer BC, Flemington EK: Epstein-Barr virus latent membrane protein 1 induces cellular MicroRNA miR-146a, a modulator of lymphocyte signaling pathways. J Virol 2008, 82:1946-1958.

11. Scaria V, Hariharan M, Maiti S, Pillai B, Brahmachari SK: Host-virus interaction: a new role for microRNAs. Retrovirology 2006, 3:68-76.

12. Grey F, Tirabassi R, Meyers H, Wu G, McWeeney S, Hook L, Nelson JA: A viral microRNA down-regulates multiple cell cycle genes through mRNA $5^{\prime}$ UTRs. PLoS Pathog 2010, 6:e1000967.

13. Motsch N, Pfuhl T, Mrazek J, Barth S, Graesser FA: Epstein-Barr virusencoded latent membrane protein 1 (LMP1) induces the expression of the cellular microRNA miR-146a. RNA Biol 2007, 4:131-137.

14. Ahluwalia JK, Khan SZ, Soni K, Rawat P, Gupta A, Hariharan M, Scaria V, Lalwani M, Pillai B, Mitra D, Brahmachari SK: Human cellular microRNA hsa-miR-29a interferes with viral nef protein expression and HIV-1 replication. Retrovirology 2008, 5:117-126.

15. Barth S, Pfuhl T, Mamiani A, Ehses $C$, Roemer K, Kremmer E, Jäker C, Höck J Meister G, Grässer FA: Epstein-Barr virus-encoded microRNA miR-BART2 down-regulates the viral DNA polymerase BALF5. Nucleic Acids Res 2008, 36:666-675.

16. Lung RWM, Tong JHM, Sung YM, Leung PS, Ng DCH, Chau SL, Chan AWH, $\mathrm{Ng}$ EKO, Lo KW, To KF: Modulation of LMP2A expression by a newly identified Epstein-Barr virus-encoded microRNA miR-BART22. Neoplasia 2009, 11:1174-U1189.

17. Song L, Liu H, Gao S, Jiang W, Huang W: Cellular microRNAs inhibit replication of the H1N1 influenza A virus in infected cells. J Virol 2010 84:8849-8860

18. Sun JZ, Wang J, Yuan D, Wang S, Li Z, Yi B, Mao Y, Hou Q, Liu W: Cellular microRNA miR-181b inhibits replication of mink enteritis virus by repression of non-structural protein 1 translation. PLOS ONE 2013, 8:e81515.

19. Goodman LB, Lyi SM, Johnson NC, Cifuente JO, Hafenstein SL, Parrish CR Binding site on the transferrin receptor for the parvovirus capsid and effects of altered affinity on cell uptake and infection. J Virol 2010, 84:4969-4978

20. Hueffer K, Govindasamy L, Agbandje-McKenna M, Parrish CR: Combinations of two capsid regions controlling canine host range determine canine transferrin receptor binding by canine and feline parvoviruses. J Virol 2003, 77:10099-10105.

21. Hueffer K, Palermo LM, Parrish CR: Parvovirus infection of cells by using variants of the feline transferrin receptor altering clathrin-mediated endocytosis, membrane domain localization, and capsid-binding domains. J Virol 2004, 78:5601-5611.

22. Mellman I: Endocytosis and molecular sorting. Annu Rev Cell Dev Biol 1996, 12:575-625

23. Palermo LM, Hafenstein SL, Parrish CR: Purified feline and canine transferrin receptors reveal complex interactions with the capsids of canine and feline parvoviruses that correspond to their host ranges. J Virol 2006, 80:8482-8492.

24. Parker JSL, Murphy WJ, Wang D, O'Brien SJ, Parrish CR: Canine and feline parvoviruses can use human or feline transferrin receptors to bind, enter, and infect cells. J Virol 2001, 75:3896-3902.

25. Glazov EA, Cottee PA, Barris WC, Moore RJ, Dalrymple BP, Tizard ML: A microRNA catalog of the developing chicken embryo identified by a deep sequencing approach. Genome Res 2008, 18:957-964.

26. Pontius JU, Mullikin JC, Smith DR, Lindblad-Toh K, Gnerre S, Clamp M, Chang J, Stephens R, Neelam B, Volfovsky N, Schäffer AA, Agarwala R, Narfström K, Murphy WJ, Giger U, Roca AL, Antunes A, Menotti-Raymond M, Yuhki N, Pecon-Slattery J, Johnson WE, Bourque G, Tesler G, O'Brien SJ, NISC Comparative Sequencing Program: Initial sequence and comparative analysis of the cat genome. Genome Res 2007, 17:1675-1689.

27. Pontius JU, O'Brien SJ: Genome annotation resource Fields-GARFIELD: a genome browser for Felis catus. J Hered 2007, 98:386-389.

28. Li R, Li Y, Kristiansen K, Wang J: SOAP: short oligonucleotide alignment program. Bioinformatics 2008, 24:713-714

29. Bland C, Ramsey TL, Sabree F, Lowe M, Brown K, Kyrpides NC, Hugenholtz P: CRISPR Recognition Tool (CRT): a tool for automatic detection of clustered regularly interspaced palindromic repeats. BMC Bioinformatics 2007, 8:209-216.

30. Krueger J, Rehmsmeier M: RNAhybrid: microRNA target prediction easy, fast and flexible. Nucleic Acids Res 2006, 34:W451-W454.

31. Huang HY, Chien $\mathrm{CH}$, Jen $\mathrm{KH}$, Huang HD: RegRNA: an integrated web server for identifying regulatory RNA motifs and elements. Nucleic Acids Res 2006, 34:W429-W434.

32. Yang $\mathrm{CH}$, Yue J, Fan M, Pfeffer LM: IFN induces miR-21 through a signal transducer and activator of transcription 3-dependent pathway as a suppressive negative feedback on IFN-induced apoptosis. Cancer Res 2010, 70:8108-8116.

33. Bookout AL, Cummins CL, Mangelsdorf DJ, Pesola JM, Kramer MF: Highthroughput real-time quantitative reverse transcription PCR. Curr Protoc Mol Biol 2006, Chapter 15:Unit 15.8.

34. Sun JZ, Wang J, Wang S, Yuan D, Birame BM, Li Z, Yi B, Liu W: MicroRNA profile analysis of a feline kidney cell line before and after infection with mink enteritis virus. Gene 2014, 539:224-229.

35. Otsuka M, Jing Q, Georgel P, New L, Chen J, Mols J, Kang YJ, Jiang Z, Du X Cook R, Das SC, Pattnaik AK, Beutler B, Han J: Hypersusceptibility to vesicular stomatitis virus infection in Dicer1-deficient mice is due to impaired miR24 and miR93 expression. Immunity 2007, 27:123-134.

36. Chen Y, Shen A, Rider PJ, Yu Y, Wu K, Mu Y, Hao Q, Liu Y, Gong H, Zhu Y, Liu F, Wu J: A liver-specific microRNA binds to a highly conserved RNA 
sequence of hepatitis $B$ virus and negatively regulates viral gene expression and replication. FASEB J 2011, 25:4511-4521.

37. Huang Y, Shen XJ, Zou QA, Wang SP, Tang SM, Zhang GZ: Biological functions of microRNAs: a review. J Physiol Biochem 2011, 67:129-139.

38. Lecellier CH, Dunoyer P, Arar K, Lehmann-Che J, Eyquem S, Himber C, Saib A, Voinnet O: A cellular MicroRNA mediates antiviral defense in human cells. Science 2005, 308:557-560.

39. Nathans R, Chu CY, Serquina AK, Lu CC, Cao H, Rana TM: Cellular microRNA and P bodies modulate host-HIV-1 interactions. Mol Cell 2009, 34:696-709.

40. Pedersen IM, Cheng G, Wieland S, Volinia S, Croce CM, Chisari FV, David M: Interferon modulation of cellular microRNAs as an antiviral mechanism. Nature 2007, 449:919-U913.

41. Aisen P: Transferrin receptor 1. Int J Biochem Cell B 2004, 36:2137-2143.

42. Cheng Y, Zak O, Alsen P, Harrison SC, Walz T: Structure of the human transferrin receptor-transferrin complex. Cell 2004, 116:565-576.

43. Kwok JC, Richardson DR: The iron metabolism of neoplastic cells: alterations that facilitate proliferation? Crit Rev Oncol Hemat 2002, 42:65-78.

44. Gatter KC, Brown G, Trowbridge IS, Woolston RE, Mason DY: Transferrin receptors in human-tissues - their distribution and possible clinical relevance. J Clin Pathol 1983, 36:539-545.

45. Chitambar CR, Massey EJ, Seligman PA: Regulation of transferrin receptor expression on human-leukemic cells during proliferation and induction of differentiation - effects of gallium and dimethylsulfoxide. $J$ Clin Invest 1983, 72:1314-1325.

46. Larrick JW, Cresswell P: Modulation of cell-surface iron transferrin receptors by cellular density and state of activation. J Supramol Struct 1979, 11:579-586.

47. Neckers LM, Trepel JB: Transferrin receptor expression and the control of cell-growth. Cancer Invest 1986, 4:461-470

48. Op De Beeck A, Caillet-Fauquet P: Viruses and the cell cycle. Prog Cell Cycle Res 1997, 3:1-19.

49. Tattersall P: Replication of the parvovirus MVM 1. Dependence of virus multiplication and plaque-formation on cell-growth. J Virol 1972, 10:586-590.

50. Davidson BL, McCray PB Jr: Current prospects for RNA interference-based therapies. Nat Rev Genet 2011, 12:329-340.

51. Geisbert TW, Lee ACH, Robbins M, Geisbert JB, Honko AN, Sood V, Johnson JC, de Jong S, Tavakoli I, Judge A, Hensley LE, MacLachlan I: Postexposure protection of non-human primates against a lethal Ebola virus challenge with RNA interference: a proof-of-concept study. Lancet 2010, 375:1896-1905.

52. Li BJ, Tang QQ, Cheng D, Qin C, Xie FY, Wei Q, Xu J, Liu YJ, Zheng BJ, Woodle MC, Zhong NS, Lu PY: Using siRNA in prophylactic and therapeutic regimens against SARS coronavirus in rhesus macaque. Nat Med 2005, 11:944-951.

53. Palliser D, Chowdhury D, Wang QY, Lee SJ, Bronson RT, Knipe DM, Lieberman J: An siRNA-based microbicide protects mice from lethal herpes simplex virus 2 infection. Nature 2006, 439:89-94.

54. Tompkins SM, Lo CY, Tumpey TM, Epstein SL: Protection against lethal influenza virus challenge by RNA interference in vivo. Proc Natl Acad Sci U S A 2004, 101:8682-8686.

doi:10.1186/s12985-014-0210-3

Cite this article as: Sun et al: MicroRNA miR-320a and miR-140 inhibit mink enteritis virus infection by repression of its receptor, feline transferrin receptor. Virology Journal 2014 11:210.

\section{Submit your next manuscript to BioMed Central and take full advantage of:}

- Convenient online submission

- Thorough peer review

- No space constraints or color figure charges

- Immediate publication on acceptance

- Inclusion in PubMed, CAS, Scopus and Google Scholar

- Research which is freely available for redistribution

Submit your manuscript at www.biomedcentral.com/submit
Biomed Central 